\title{
Study on the Training Mode for Foreign Railway Talents Under China's
}

\section{High-Speed Railway "going out”}

\author{
Jin Jing ${ }^{1, a, *}$, Li Dong ${ }^{2, b}$ and Liu Shuai ${ }^{2, c}$ \\ ${ }^{1}$ China Academy of Railway Sciences, Beijing100081, China; \\ ${ }^{2}$ Beijing Jiaotong University, Beijing100044, China.

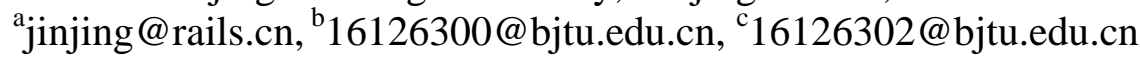 \\ *corresponding author
}

Keywords: Training mode, high-speed railway going out, international training.

\begin{abstract}
Under the background of high-speed railway "going out", education and training play a crucial role in promoting international railway projects and advocating China railway standard and technical system. However, there is no existent systematic training mode for foreign railway talents and this paper will construct a new training mode to facilitate China's high-speed railway going out.
\end{abstract}

\section{Introduction}

Under the background of the Belt and Road Initiative, China's burgeoning high-speed railway (herein after referred to as HSR) industry is on its way of going global, which requires the interconnection of HSR infrastructure construction. The foreign training program is importanttospeeding up the pace of "going out" for China's HSR industry, which is initiated by China's government, based on which the foreign aid training program for government officials from the underdeveloped third world countries is organized by the Ministryof Commerce with the goal of introducing China's railway system and related technical system. While the foreign railway talents training program based on the "going out" project is more targeted, stressing seamless link-up between training and working and ensuring trainees competent for the future jobs. Under the background of HSR "going out” project, this paper proposes aHSR foreign talents training mode.

\section{Training philosophies and principles}

\section{1) Advanced overall planning}

Most of the "going out" HSR projects focus more on engineering construction and cost budgeting, leaving the talent needsunderestimatedin the bidding stage. The foreign training program usually responsepassively to the needs of foreign countries, lacking the top-level design which could give an overall guidance for the program.

2)Optimization of resource integration and allocation

HSR foreign talents training involve multiple levels and numerous posts, the training scale of which is quite large. Therefore,it's difficult for one institution to undertake the overall training programindependently, the integration of training resources is required, forming a "foreign talents training union", whose main responsibilities include promoting exchanges among schools and enterprises, integrating education resources of all parties. Based on the union,a standard system for talents training needs to be established to standardize the overall process and to ensure the quality of training.

3)Results-oriented and innovation-oriented

China's HSR talents training includes theoretical study and onsite practice, the training duration of which is relatively long,making it impractical to have all the foreign talents trained in China. To solve this problem, more results-oriented objectives focusing on practical operational skills and post competence need to be proposed. With the shortage of localized training resources, more innovative 
training methods like online training and VR technology are adopted. At the same time, the quantifiable process evaluation method is applied to adjust training content according to local conditions and according to the trainees' needs.

\section{The foreign talents training mode}

Based on the HSR "going out” project, a customizedsystematic foreign talents training mode is proposed. The mode is a locked loop including talent needs analysis, training plan building, training implementationand training effect evaluation, with the whole process under quality monitoring. The trainees are classified into three levels, based on which the training contents and training methods are formed accordingly. Theresources integration lays a solid foundation for training implementation. This modeprovides long-term support for the target country from three aspects. The effect evaluation is also set in different stages to provide feedback for the next training process.

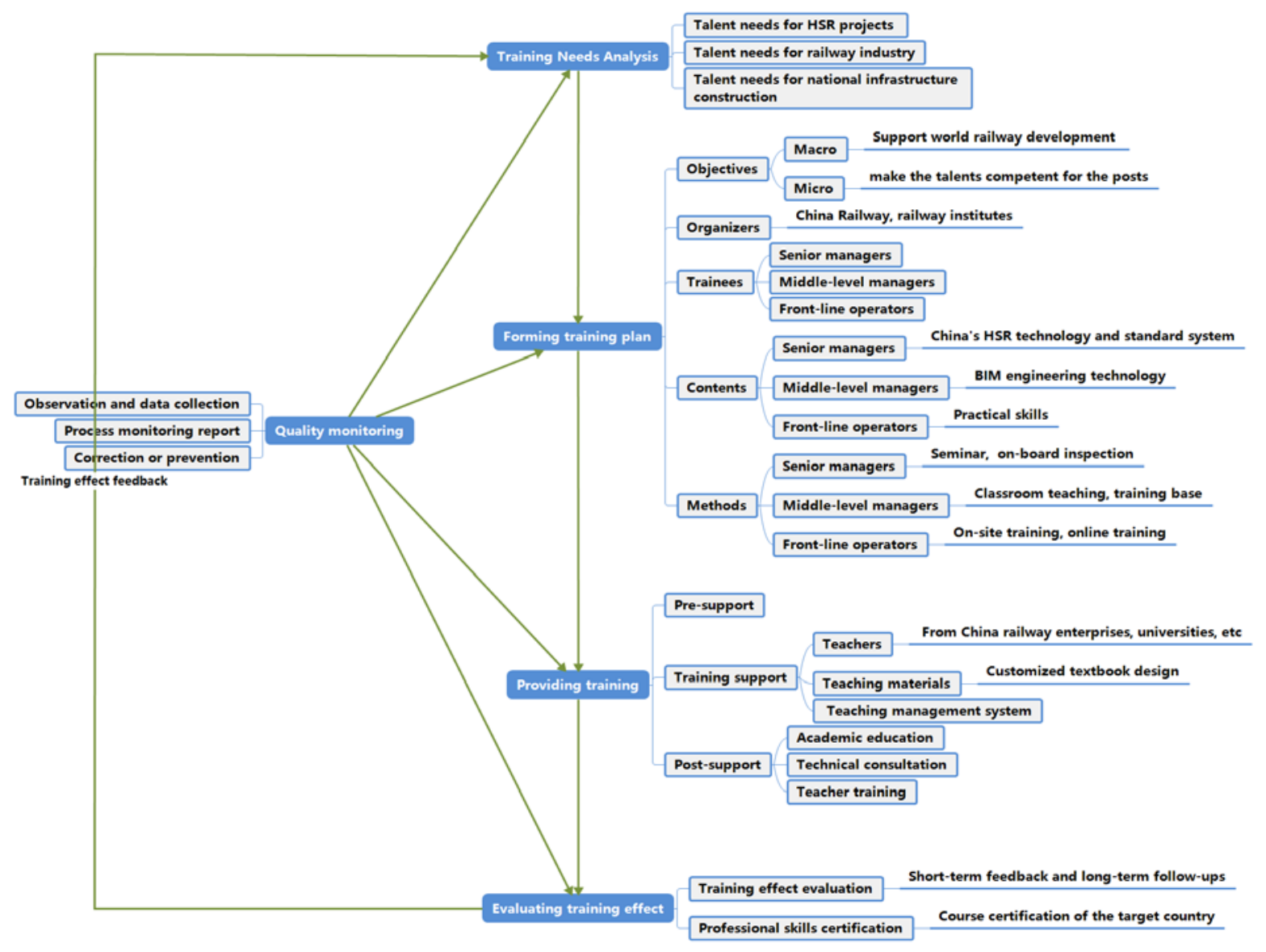

\subsection{Training needs analysis}

Fig. 1The foreign talents training mode

At present, China's "going out" railway projects are mainly targeted to the underdeveloped countries with no existing HSR standard or technical system. This mode aims to provide long-term support for these countries in terms of talents training and education. Under the guidance of "Operation-Task-Person Analysis" proposed by McGehee and Thayer, this chapter analyzes talent needs from three dimensions: HSR projects, railway industry and national infrastructure construction.

1) Talent needs for HSR projects

According to the UIC statistics released in March 2017, regions including southeastAsia, central Asia and south Asia are paying more attention to railway infrastructure construction, the length of the high-speed railway construction project under planning in these regions has reached 56485km. Many of China's neighboring countries have cooperated with us in building railways. Countries that are building or are about to build railways are in urgent need for large numbers of technical 
personnel to promote the exploration, design, production, construction, management and service projects to support the coming and on-going HSR projects.

2) Talent needs for railway industry

With the advancement of the Belt and Road Initiative, UIC statistics released in March 2017 show that among the countries and regions that have signed with China on cooperating in HSR construction, most that plan to build HSR in the future are developing countries in Asia and Europe. Withthe lack of rail transit major and professional teachers, the professional education infrastructure in these countries is backward. Therefore, the "inviting in" and "going out" strategy need to be adopted to reserve teachers for the rail transit industry and to carry out continuing education for existing talents, which can improve technologies for HSR construction.

3)Talent needs for national infrastructure construction

The infrastructure connectivity is emphasizedin the Belt and Road Initiative. Railway infrastructure construction planning not only promote national economic and trade exchanges, push economic development, but also promote economic and trade exchanges among countries and relieve the overcapacity of market resources. Therefore, the countries with inadequate infrastructure need to carry out large-scale HSR infrastructure construction at the early stage.

\subsection{Drawing up a training plan}

\section{(1) Training objectives}

With the rapid development of HSR construction, a lot more all-round personnel need to be trained and pooled. The aim of carrying out foreign personnel training is to deepen cooperation by sharing technical skills, strengthen international exchanges,promoting China's HSR "going out" strategy.

(2) Training organizers

Foreign talents training is undertaken and co-organized by the China Railway, railway enterprises and universities, relying on the integration of educational resources and practical operations.

(3) Trainees

According to the training requirements of different HSR majors, the foreign HSR trainees are divided into three levels, which are senior managers, middle-level managers and front-line operators. The training of senior managersaims to introduce China's HSR system and advanced HSR technology; the training of middle-level managers aims to impart key skills, ensuring that they can undertake professional tasks; the training purpose for front-line operators is to make sure the trainees are equipped with operational capacity and necessary post skills.

(4) Training contents

The training contents for foreign talents mainly consist of two aspects: knowledge training and skill training. Knowledge training aims to introduce China's HSR technology and standardsystem,impart theoretical knowledge andimprove the ability of handling emergency. Skill training aims to improve practical operation skills, key technical skills and on-site operation efficiency.

(5) Training methods

The methods of foreign talents training consist of classroom teaching, on-site practice, online training, etc. The combination of these methods can lead to better effect.Most importantly, the training methods are chosen accordingly to the requirements of three talent levels.

\subsection{Training implementation}

Foreign talents training program under China's HSR “going out” strategy is jointly carried out by three parties: the government, enterprises and higher education institutions. During the training, the government and railway enterprises provide policy, capital and management support and higher education institutions provide theoretical support by compiling personalized textbooks which are closely related to the front-line operating requirements. 


\subsection{Training effect evaluation and feedback}

Systematic and long-term evaluation standards are established according to the training duration. After the training, according to the assessment results, the overall training assessment report will be given and the feedback of training quality can be obtained through long-term follow-ups, through which China's foreign talents training strategy can be improved.

\section{Conclusions}

To facilitate China's HSR going out, a customized systematic foreign talents training mode is proposed in this paper targeted at HSR projects, which can provide sustainable support for HSR construction and technology development in targeted countries and valuable reference for Chinese railway companies to bid for international HSR projects.

\section{Acknowledgments}

This work was financially supported by Foundation project of China Academy of Railway Sciences "Talents Cultivation Mode and Implementation Plan for Foreign Management and Technical Personnel Adapting to China High-speed Railway Going Global”, project No.:2016YJ150.

\section{References}

[1] Yanhua Di, High-speed railway skilled workers training project training mode research, Southwest Jiaotong University. 47 (2013) 4-10.

[2] A. Bena MD, E Berchialla, M. E. Coffano. Effectiveness of the training program forworkers at construction sites ofthehigh-speed railway line, American Journal of Industrial Medicine. 12(2010)965-972.

[3] Kirkpatrick, D. L. Evaluating training programs. Berrett-Koehler Publishers, San Francisco, 1994.

[4] Brown, Stephen M., Seidner, Constance J. Evaluating corporate training: models and issues. (Eds.) Springer Netherlands, Berlin,1998. 113-140.

[5] Information on http://news.switu.edu.cn/shownews- 7736-0-1.shtml. 